\title{
Occupational exposure and asthma control
}

\author{
Dick Heederik
}

Affiliation: Institute for Risk Assessment Sciences, Utrecht University, Utrecht, The Netherlands.

Correspondence: Dick Heederik, Institute for Risk Assessment Sciences, Utrecht University, IRAS EEPI Division, PO Box 80178, Utrecht 3583 VH, The Netherlands. E-mail: d.heederikquu.nl

@ERSpublications

Poor control of asthma may be the result of ongoing exposure to disinfectants http://ow.ly/njzC30fJFMj

Cite this article as: Heederik D. Occupational exposure and asthma control. Eur Respir J 2017; 50: 1701951 [https://doi.org/10.1183/13993003.01951-2017].

In this issue of the European Respiratory Journal, Dumas et al. [1] describe associations between occupational disinfectant exposure and asthma control in US nurses. Asthma control was defined by using the Asthma Control Test (ACT) and based on responses to five questions on activity limitations, frequency of symptoms and frequency of use of quick-relief medication in the past 4 weeks ( $\beta$-agonist inhaler, e.g. albuterol, for symptom control). This instrument is not commonly considered an end-point in studies on occupational exposures and asthma, while asthma control is of particular relevance for asthma patients at work. Thus, the use of asthma control using the ACT is of particular interest [2]. According to the Global Initiative for Asthma Statement, asthma control is the extent to which manifestations of asthma can be observed, or have been reduced or removed by treatment. Asthma control has two dimensions; treatment of symptoms and future risk of adverse outcomes. Variables that can determine future adverse outcomes are lung function, exposure to allergens and non-specific stimuli (smoking, indoor and outdoor air quality), socio-economic and psychological problems, comorbidities and eosinophilia. These variables also determine future outcomes of occupational asthma. The ACT includes a limited set of these, in particular variables associated with treatment of symptoms.

Dumas et al. [1] made use of a large cohort study that had been established in 1989. Nurses with asthma were invited in 2014 to complete two questionnaires on their current occupation and asthma. A population of more than 4100 asthmatic nurses was available for analysis. Information on disinfectant use was collected earlier, in 2013, in an independent random sample of more than 9000 nurses. The questionnaire responses on exposure to disinfectants were used to assess the likelihood of exposure for all existing relevant job-task combinations based on self-reports. This resulted in a job-task-exposure matrix for seven major disinfectants/cleaning products (formaldehyde, glutaraldehyde, hypochlorite bleach, hydrogen peroxide, alcohol, quaternary ammonium compounds and enzyme-based cleaners) which was used to assign exposure to each individual in the study on the basis of their job-task combination. For more than 4000 individuals, complete data was available on disinfectant use in healthcare institutions and on asthma and asthma control.

The effect of disinfectant exposure on asthma control had odds ratios that varied between 1.10 and 1.33 for one decrease in asthma control category, adjusted for age, smoking status, body mass index, race and ethnicity. For five out of seven disinfectants these associations were statistically significant (formaldehyde, glutaraldehyde, hypochlorite bleach, hydrogen peroxide and enzyme-based cleaners). These associations seem weak to moderately strong, but are not likely explained by study design or exposure assessment methodology. Exposure assessment on the detailed job-task level is considered the optimal approach

Received: Sept 252017 | Accepted: Sept 262017

Conflict of interest: None declared.

Copyright OERS 2017 
associated with limited exposure misclassification and thus potential underestimation of exposure response relations [3-6]. These relatively modest associations should not be interpreted as indicative for a limited role for disinfectant exposure with regard to asthma.

In surveys in hospital personnel, using similar generally similar methodologies, strong associations have been observed between disinfectant exposure and asthma [7-11]. For instance, a study in seven healthcare institutions in France showed that exposure to quaternary ammonium compounds, a specific disinfectant with the exposure assessed through a very detailed approach, increased significantly the risk of reported physician-diagnosed asthma and nasal symptoms at work (adjusted odds ratios 7.5 and 3.2, respectively). All the above-mentioned studies indicate that many workers in healthcare have an occupational exposure to disinfectants; percentages vary but range from $30-60 \%$. The strong associations, in combination with the fact that many are exposed, suggests that many asthma cases would not have occurred without disinfectant exposure.

The more detailed analyses presented by Dumas et al. [1] shed some more light on the role of disinfectant exposure and asthma control. In particular, cleaning of medical instruments was more strongly related to poor and very poor asthma control. The use of sprays was also considerably more strongly associated with asthma control; asthmatic patients with poor and very poor control appeared to use sprays more often. Combined exposure, to different disinfectants, was also indicative of poor asthma control. These relationships seem plausible because some specific activities are likely to be associated with higher exposure levels, multiple exposures, or longer duration of exposure $[6,12,13]$. In particular, sprays are believed to lead to higher exposure than classical wet application of disinfectants. In a recent study, it was shown that individuals reported symptoms more frequently when they worked on departments with higher exposure levels [14]. Recent biomarkers studies for disinfectant by-products have also shown that nurses are more exposed to a range of chemicals in comparison to the general population [6]. Thus, activities indicative of relatively high and combined exposure are particularly associated with poor asthma control.

There is a general belief that continuing occupational exposure in individuals with occupational asthma influences their prognosis negatively [15]. Exposure reduction is associated with a more limited improvement of asthma compared to exposure cessation, but objective information on the magnitude of the exposure reduction is generally absent and this sheds doubt on the quality of these exposure cessation studies [16]. This conclusion is mainly based on studies in asthmatic subjects who were sensitised to agents in the work environment. No or very little information is available for other phenotypes. The study by Dumas et al. [1] provides little information on the asthma phenotypes involved in their study. Poor asthma control was not associated with childhood asthma or adult onset asthma, but little additional phenotypical information was available. Disinfectants are often irritants; some are sensitising agents or have adjuvant properties [7, 17-21]. Asthma control may differ between patients with different underlying causes of symptoms, but to be able to study this aspect, more detailed phenotypical information is required. A complication is that the mechanisms by which disinfectants and cleaning products affect respiratory health are, to a large extent, still unclear [22]. There is a need for more information on underlying mechanisms, particularly because this could also help understand long term risks and prognosis [20]. For instance, it remains a question whether poor asthma control was due to ongoing exposure to disinfectants in patients with work-related or irritant-induced asthma, similar to the worse outcome in occupational asthma caused by continuing exposure to sensitising agents.

Disinfectants are used to clean medical devices and surfaces to prevent transmission of nosocomial infections. The use of these agents will continue. Unfortunately, occupational disease registries see a disproportionately high number of cases of work-related asthma occurring in healthcare occupations due to disinfection and cleaning products, with the majority of cases in nursing, operating theatre personnel, endoscopy and radiology staff $[23,24]$. In combination with the mounting evidence regarding the asthma risks associated with these chemicals, there is a need for exposure reduction to control development of asthma and improve asthma control in exposed individuals. Respiratory physicians should be aware of the fact that many of their colleagues may have developed asthma in the healthcare industry and need appropriate treatment. Exposure reduction should be part of the remedy offered, and some recommendations are available on how to limit exposure without increasing the risk of spreading infectious diseases [25].

\section{Acknowledgements}

Jos Rooijackers contributed with some critical comments to earlier versions of this manuscript.

\section{References}

1 Dumas O, Wiley A, Quinot C, et al. Occupational exposure to disinfectants and asthma control in US nurses. Eur Respir J 2017; 50: 1700237. 
4 Bello A, Quinn MM, Perry MJ, et al. Characterization of occupational exposures to cleaning products used for common cleaning tasks--a pilot study of hospital cleaners. Environ Health 2009; 8: 11.

5 Quinot C, Dumas O, Henneberger PK, et al. Development of a job-task-exposure matrix to assess occupational exposure to disinfectants among US nurses. Occup Environ Med 2017; 74: 130-137.

6 Ioannou S, Andrianou XD, Charisiadis $\mathrm{P}$, et al. Biomarkers of end of shift exposure to disinfection byproducts in nurses. J Environ Sci (China) 2017; 58: 217-223.

7 Gonzalez M, Jegu J, Kopferschmitt MC, et al. Asthma among workers in healthcare settings: role of disinfection with quaternary ammonium compounds. Clin Exp Allergy 2014; 44: 393-406.

8 Dumas O, Donnay C, Heederik DJ, et al. Occupational exposure to cleaning products and asthma in hospital workers. Occup Environ Med 2012; 69: 883-889.

9 Mirabelli MC, Zock JP, Plana E, et al. Occupational risk factors for asthma among nurses and related healthcare professionals in an international study. Occup Environ Med 2007; 64: 474-479.

10 Delclos GL, Gimeno D, Arif AA, et al. Occupational risk factors and asthma among health care professionals. Am J Respir Crit Care Med 2007; 175: 667-675.

11 Arif AA, Delclos GL. Association between cleaning-related chemicals and work-related asthma and asthma symptoms among healthcare professionals. Occup Environ Med 2012; 69: 35-40.

12 Saito R, Virji MA, Henneberger PK, et al. Characterization of cleaning and disinfecting tasks and product use among hospital occupations. Am J Ind Med 2015; 58: 101-111.

13 LeBouf RF, Virji MA, Saito R, et al. Exposure to volatile organic compounds in healthcare settings. Occup Environ Med 2014; 71: 642-650.

14 Casey ML, Hawley B, Edwards N, et al. Health problems and disinfectant product exposure among staff at a large multispecialty hospital. Am J Infect Control 2017; 45: 1133-1138.

15 Vandenplas O, Dressel H, Nowak D, et al. What is the optimal management option for occupational asthma? Eur Respir Rev 2012; 21: 97-104.

16 Vandenplas O, Dressel H, Wilken D, et al. Management of occupational asthma: cessation or reduction of exposure? A systematic review of available evidence. Eur Respir J 2011; 38: 804-811.

17 Nielsen GD, Larsen ST, Olsen O, et al. Do indoor chemicals promote development of airway allergy? Indoor Air 2007; 17: 236-255.

18 Preller L, Doekes G, Heederik D, et al. Disinfectant use as a risk factor for atopic sensitization and symptoms consistent with asthma: an epidemiological study. Eur Respir J 1996; 9: 1407-1413.

19 Bernstein JA, Stauder T, Bernstein DI, et al. A combined respiratory and cutaneous hypersensitivity syndrome induced by work exposure to quaternary amines. J Allergy Clin Immunol 1994; 94: 257-259.

20 Vizcaya D, Mirabelli MC, Orriols R, et al. Functional and biological characteristics of asthma in cleaning workers. Respir Med 2013; 107: 673-683.

21 Malo JL, Chan-Yeung M. Agents causing occupational asthma. J Allergy Clin Immunol 2009; 123: 545-550.

22 Siracusa A, De Blay F, Folletti I, et al. Asthma and exposure to cleaning products - a European Academy of Allergy and Clinical Immunology task force consensus statement. Allergy 2013; 68: 1532-1545.

23 Walters GI, Moore VC, McGrath EE, et al. Agents and trends in health care workers' occupational asthma. Occup Med (Lond) 2013; 63: 513-516.

24 Paris C, Ngatchou-Wandji J, Luc A, et al. Work-related asthma in France: recent trends for the period 2001-2009. Occup Environ Med 2012; 69: 391-397.

25 Quinn MM, Henneberger PK, Braun B, et al. Cleaning and disinfecting environmental surfaces in health care: toward an integrated framework for infection and occupational illness prevention. Am J Infect Control 2015; 43: $424-434$. 